\title{
Meet-Up: An Orientation Program for Students with Autism Spectrum Disorder
}

\author{
David Lopez ${ }^{1}$, Lídia Montero ${ }^{2}$, Montserrat Vilalta ${ }^{3}$ \\ 1: Institute of Education Sciences, 2: Statistics and Operations Research Department, \\ 3: Innovation and Community Bureau - Inclusion Office \\ Universitat Politècnica de Catalunya - BarcelonaTech \\ Barcelona, Spain \\ david@ac.upc.edu, lidia.montero@upc.edu, montserrat.vilalta@upc.edu
}

\begin{abstract}
This innovate practice work-in-progress paper presents a pilot orientation program for students with Autism Spectrum Disorder (ASD), a range of conditions involving serious dysfunctions in aspects of social relationships and learning. Young adults with ASD are more likely than the general population to concentrate on science and engineering, so those who enroll at college tend to choose STEM degrees. However, students with ASD often undergo stress and experience difficulty in the transition to college. For this reason our university considers the necessity for an orientation program to help such students in this challenging situation. In this paper, the authors describe this initiative, known as Meet-Up, and the problems we faced during the pilot program.
\end{abstract}

Keywords - mentoring, orientation, student attraction, student retention, Autism Spectrum Disorder

\section{INTRODUCTION}

This innovate practice work-in-progress paper presents the design and initial results of a pilot orientation program for students with Autism Spectrum Disorder (ASD). The Universitat Politècnica de Catalunya - BarcelonaTech is a technical university that only provides studies in the STEM (Science, Technology, Engineering and Mathematics) area. As part of our Inclusion Program, our university has been offering orientation programs for students with special needs: physical disabilities, Attention Deficit Hyperactive Disorder (ADHD), dyslexia, and so on. However, this is the first time we have designed a program for students with an ASD. Since the faculty at our university has little experience of students with these disorders, the program was designed with the help of a local Autism Spectrum Association. In this paper, the experience is described and the initial results analyzed and qualitatively evaluated using the narrative methodology.

\section{AUSTISM SPECTRUM DISORDER}

\section{A. Young adults with ASD and post-secondary education}

Autism Spectrum Disorder (ASD) refers to a range of conditions involving serious dysfunctions regarding social relationships and learning. According to Baron-Cohen [1], students with an ASD tend to have a notable aptitude for systemizing (i.e. analyzing and constructing a rule-based system), but are below average with regard to empathy (i.e. social or emotional reactions to other people's thoughts and feelings). These students often show stress and difficulty when faced with new situations such as the transition to college, which can be particularly challenging for them.

Individuals with an ASD typically have above average intellectual abilities and an interest in focused areas in which they can develop expertise, as well as a remarkable ability to think divergently [2]. Despite these skills, these young adults must deal with problems involving nonverbal communication, social skills, resistance to change, and sensorial challenges, as well as difficulty in understanding their emotions and the emotions of others, which may lead to a feeling of loneliness and isolation that is liable to provoke failure at college [3]. On the other hand, college may provide an environment that can help such individuals to promote personal competencebuilding, increase self-confidence and integration into a community, as well as improving their future employment prospects and quality of life [4].

Nowadays, colleges and universities are receiving more admission applications from young adults diagnosed with ASD [5]. In the past, ASD was sometimes confused with other disorders, but since the late 1990s the revision of the Diagnostic and Statistical Manual of Mental Disorders (DSMIV-TR [6]) has had an important impact on early diagnosis and intervention of ASD, so many of these students are now in a position to consider enrollment at university, which was not a viable option a few years ago. Unfortunately, young adults with ASD have particular needs that differ in some respects from the requirements of other students; in particular, social and emotional support to deal with deficits in certain areas, and with the fear and anxiety that typically accompany these conditions [7]. Individuals with an ASD pose challenges to Higher Education Institutions, because these conditions are not as obvious as some physical and more commonly understood disabilities.

\section{B. Students with ASD especial needs}

In order to understand the needs of students with an ASD, we recommend the comprehensive study on current practices by Barnhill [7], where the author remarks that "the autism spectrum is a wide spectrum and each individual is different. Strategies that work for one individual may not work for

(C) 2018 IEEE. Personal use of this material is permitted. Permission from IEEE must be obtained for all other uses, in any current or future media, including reprinting/republishing this material for advertising or promotional purposes,creating new collective works, for resale or redistribution to servers or lists, or reuse of any copyrighted component of this work in other works. 
another". Among others, the study recommendations for assisting students with an ASD include the following:

- Tailor to the individual and not to the diagnosis

- $\quad$ Provide a quiet space on campus, available 24 hours a day for ASD students

- Encourage students with an ASD to tutor other students in their area of expertise

- Take into account housing options and the advantages and disadvantages of a single room

- Use technology to help them organize day-to-day work or provide access to information that usually is taken for granted in other students

- Provide assistance in organizing space in the classroom

- Provide predictable class routines, and tools for managing anxiety and stress

\section{Young adults with ASD and STEM studies}

Wei et al [8] have shown that individuals with an ASD are more likely than other disability groups to gravitate towards STEM, perhaps because the systematization in these courses is higher than in others. Furthermore, it has also been demonstrated that science and engineering students are less accustomed to mutual collaboration than those enrolled in other studies [9]. In addition, young adults with an ASD are more likely than the general population to pursue subjects such as science and computer science. Chen [10] demonstrates that the STEM major rate for people with an ASD is higher than that of students from the general population. Some recent studies exist on the needs of college students on the autism spectrum and the initiatives to deal with these requirements ([7], [11], [12], [13], among others), but very few devoted specifically to STEM degrees [8][14]. More research is needed in this field.

\section{ThE MEET-Up Program}

\section{A. Background}

Our university created its first Disability Assistance Program in 2007, which belongs to the Office for Inclusion at the Innovation and Community Bureau. It reflects the will of the university to implement the basic principles of equal opportunities for people with disabilities. Since its inception, the office has formed part of UNIDISCAT and SAPDU, the Catalan and Spanish University and Disabilities networks.

The inclusion services are aimed at students with unique needs who require some support or adaptation for the development of their activity. The functions of the service are as follows: to provide direct and specialized attention; to detect new needs; to design and develop the required actions in collaboration with the schools and other services of the university; and finally, to respond to the needs of adaptation and habilitation arising from situations of disability and special educational needs of the student. To date, the inclusion service has been working with people with both physical (deafness, blindness) and mental (Attention Deficit Hyperactive Disorder - ADHD, dyslexia) disabilities. This is the first time a service for young adults with an ASD has been included.

Other Universities such as the University of Edinburgh ${ }^{1}$ and the University of Leeds ${ }^{2}$ provide similar programs for the purpose of helping students with disabilities, but our program has largely been inspired by the experience of the University of Oslo [15]. A workshop entitled "Supporting Students with Asperger Syndrome at the University of Oslo" by Kari Steindal was held in Barcelona in October, 2015, with a focus on the integration of people with disabilities at university, and organized by our government. Members of the Meet-Up program attended this workshop.

\section{B. Description}

As Chown and Bevan [5] stated, "understanding autism is often counter-intuitive for neurotypical college staff". Thus, a local Autism Spectrum Association (Associació Asperger de Catalunya) was contacted with a request for help, and experts from this Association supervised the design of the program and conducted all the face-to-face meetings.

The program was issued publicly at the time of enrollment (June), so that all students and not only first-year students were aware of its existence.

The program consisted of a series of face-to-face meetings with the students forming the pilot group. The objectives of these meetings were as follows:

- To combat isolation and loneliness: make students aware that they are not alone. Help them to build a friendship network,

- To pre-empt additional difficulties: Reduce stress, obtain support and understanding from others,

- Identity development: Recognize themselves in others, increase self-esteem, learn how to tell others about ASD, and

- Learn social rules and communication skills: make the group itself a place for social interaction and social competence training in a safe environment.

The first meeting was held in September, 2017, and consisted of a visit to the Campus and the classrooms, library and dining rooms, together with an explanation of the basic elements of daily life at the college. This kick-off session was addressed to new students, but taking into account that it was a brand new experience, all the students at our university with an ASD and other disabilities were invited to join the group. The University Moodle-based virtual campus was also presented during this session. The meeting was focused on organizing day-to-day work as well as how to link our virtual campus schedule with exam dates, class organization and location, deliverables and so on. Students were also asked to

\footnotetext{
${ }^{1} \mathrm{https}$ ://www.ed.ac.uk/student-disability-service/student-support/support-weoffer/support-for-students-with-asperger-s-syndrome

2 http://students.leeds.ac.uk/disabledstudents
} 
share their schedules with the Meet-Up staff in order to help them to organize their agenda. A common space for these students was made available in our virtual campus where information could be shared, including a description of the general bachelor program and documentation for the subsequent face-to-face meetings.

As not all individuals with an ASD face the same challenges, students were asked to complete the ASWI (Asperger Syndrome Workplace Interview) questionnaire by Arne Svensdrud and Kari Steindal from Norway. The University and Research Department of the Catalan Government provided us with a version in English of the questionnaire and this was translated into our own language. It consists of an interview guide containing 142 items designed to help students describe their own personal challenges so they can find ways of dealing with them or take them into account in the college environment. With this tool and the individual interviews, the Meet-up team was able to tailor the program to the individual needs of students, who were also asked if they required any special working conditions, such as a fixed location in the campus library or adaptation of exams. These types of requests are usually made ad personam.

The follow-up sessions were held on a monthly basis, and topics covered in these sessions were as follows:

1. November 9, 2017: Social abilities (I)

2. December 14, 2017: Study methods and organization

3. February 15, 2018: How to deal with anxiety (I)

4. March 15, 2018: How to deal with anxiety (II)

5. April 12, 2018: Social abilities (II)

6. May 10, 2018: How to start new relationships

7. June 21, 2018: Closing session of the program

The meetings were held at lunchtime, always at the same time and place, in order to provide students and Meet-Up staff with a familiar environment and a relaxed atmosphere conducive to free and open discussion.

Finally, we experimented with the use of technology as a tool for cognitive support to help students focus on independence and control in order to reduce stress. In this initial stage, we confined the experience to electronic agendas, a contact list using WhatsApp and access to the virtual campus by means of smartphones.

\section{RESULTS}

The first session was attended by seven individuals with an ASD (five males and two females), three of whom attended most of the subsequent sessions. One student attended only the first session and then left the program, but has shown regular attendance at college, while another also attended the first session before deciding to study at home and come to the university only to do the final exams. One student left the university after a few weeks, while in the case of another, who also left the program, we have had no further information.
The quantitative assessment of a program of this nature does not provide as much information as a qualitative assessment. For this reason, the students were asked to comment on their experience in terms of what they had found helpful and if they had any suggestions about changes to the program in order to make it more useful.

Among the answers received, we highlight the following (translated from our language):

"The transition to university studies is difficult; sessions should be concentrated at the beginning of the course, even before starting the classes, although the monthly sessions are helpful".

"The techniques acquired for detecting anxiety, resolving situations requiring social skills, and the discussions have helped me as a form of group therapy and have given me the opportunity to share and discuss some of my own doubts and concerns".

"I would include more talks on study techniques and how to handle situations where you need to communicate directly with the teachers to explain learning difficulties".

"I would include debates at the university about positive discrimination in education, its advantages and possible disadvantages: social stigma, lack of understanding or ability to collaborate with teachers, etcetera".

"The meetings are useful, but there are still some issues pending; we didn't cover everything we wanted to address; more sessions should be held or organized better ".

"I found the student group discussions about how we deal with situations in everyday life to be quite productive".

"Other interesting topics to deal with could be: family and friends, non-verbal expression, feelings, perspectives on life and social impositions".

"I think it would be interesting to talk about the ASD with people who do not have it, and about the adaptation or acceptance of ASD"

Further results concern how the project helps to visualize the need for this kind of program. We are pleased to announce that Barcelona City Hall has provided us with a grant of $€ 3,355$ to organize training and awareness-raising courses on ASD for the professors and administration staff of our university. Other Catalan universities have also expressed an interest in replicating the Meet-Up program and the training courses.

\section{DISCUSSION}

While these results may seem discouraging, they are similar to those we have observed from other experiences. It should be borne in mind that many of the students with an ASD do not wish to be identified and neglect to inform the university about their difficulties. Indeed, some of those who signed up for the program presented very extreme cases. It is necessary to ensure that students with an ASD feel enough confidence in the program to join it, without any concern other than acquiring tools that will help them in their university life. 
We have learned that the efforts made to promote the program are fundamental for its success. Since this first occasion consisted of a pilot program, it was only announced to students who had already registered at our university. However, if we wish to reach more students, especially young students who are concerned about the difficulties that university life might pose for them, it is essential that they are aware some years in advance that a program such as this exists, in order to encourage them to give serious consideration to their future as university students.

For this reason, the program was publicly announced at the Saló de l'Ensenyament, an annual event during which students are informed about what the university system has to offer in our region. Students who attend this event are usually between 15 and 18 years of age. Furthermore, family associations whose members may be affected by ASD, as well as primary and secondary schools and specialists in this field, are also provided with this information. The program this year was presented at a conference held on child psychiatry in which special attention was given to Asperger syndrome.

We believe that raising public awareness of this program may increase the number of students who decide to make the decision to go to university. Since the results of this initiative may take several years to materialize, it is therefore necessarily a long-term project. However, we are convinced that a university such as ours has a duty to society to provide this type of help to its most vulnerable students.

In the short term, some changes in the face-to-face sessions are under consideration in order to accommodate students' suggestions. In addition, for the purpose of extending the availability of tools for students joining the program, the creation of an application for smartphones is being planned to help in guidance within the campus. Furthermore, training and awareness-raising courses on ASD for the professors and administration staff of our university were designed and put into practice last June.

\section{CONCLUSIONS}

This work-in-progress paper presents an orientation program for students with Autism Spectrum Disorder (ASD). Since early diagnosis and intervention is growing in this field, more students with ASD are expected to matriculate for college in the near future. All higher education institutions should incorporate programs to guide these young adults through their experience at university, and more importantly, programs such as that set out here are required to encourage students with ASD who are faced with the difficulties involved in adapting to life at university. This would ensure that they receive the necessary support to prevent any disability from influencing their decision of whether or not to enroll at the university.

Our future work will focus on improving this orientation program by developing technological tools to help students in the challenges they face on entering university, and by providing them more opportunities to achieve success in their studies. Once this process has been refined, we intend to study the specific needs of young adults with an ASD who wish to pursue STEM courses, with the aim of identifying these difficulties and adapting our program accordingly.

\section{ACKNOWLEDGMENT}

First of all, we wish to thank the students who enrolled in the Meet-Up pilot project for their courage and strength. We also wish to thank Marta Mas Rey, Natàlia Radó Graupera and Mireia Gracia Blanes, psychologists from the Catalan Asperger Association, for their invaluable help and commitment with the project.

\section{REFERENCES}

[1] S. Baron-Cohen. "Autism: the empathizing-systemizing (E-S) theory". Annals of the New York Academy of Sciences, 1156(1), 68-80. 2009.

[2] J.Q. Morrison, F.J. Sansosti, and W.M. Hadley. "Parent Perceptions of the Anticipated Needs and Expectations for Support for their Collegebound Students with Asperger's Syndrome". Journal of Postsecondary Education and Disability. 22:78-87. 2009

[3] K. Ashbaugh, R.L. Koegel, and L.K.Koegel. "Increasing Social Integration for College Students with Autism Spectrum Disorder". Behavioral Development Bulletin, 22(1):183-196. 2017

[4] D. Hart, M. Grigal, and C. Weir, C. "Expanding the Paradigm: Postsecondary Education Options for Individuals with Autism Spectrum Disorder and Intellectual Disabilities". Focus on Autism and Other Developmental Disabilities, 25:134 -150. 2010.

[5] N. Chown and N. Beavan. "Intellectually Capable but Social Excluded? A Review of the Literature and Research on Students with Autism in Further Education". Journal of Further and Higher Education 36: 477493. 2012

[6] American Psychiatric Association. "Diagnostic and Statistical Manual of Mental Disorders (4th ed). Whashington DC 2000.

[7] G.P. Barnhill. "Supporting Students with Asperger Syndrome on College Campuses: Current Practices". Focus on Autism and Other Development Disabilities. 31(1):3-15. 2016

[8] X. Wei, J.W. Yu, P. Shattuck, M. McCracken, and J. Blackorby. "Science, Technology, Engineering, and Mathematics (STEM) Participation Among College Students with an Autist Spectrum Disorder". Journal of Autism and Developmental Disorders. 43(7): 1539-1546. 2013.

[9] M. Guzdial, P. Ludovice, M. Realff, T. Morley, and K. Carroll. "When collaboration doesn't work". In Proceedings of the International Conference of the Learning Sciences, Mahwah, NJ, USA. 2002.

[10] X. Chen. "Students Who Study Science, Technology, Engineering, and Mathematics (STEM) in Postsecondary Education. Stats in Brief". NCES 2009-161. National Center for Education Statistics. 2009.

[11] S. Shmulsky, K. Gobbo, and A. Donahue. "Groundwork for Success: A college transition Program for Students with ASD”. Journal of Postsecondary Education and Disability, 28(3), 235-241. 2015.

[12] B.E. Cox, et al. "College experiences for students with Autism Spectrum Disorder (ASD): Personal identity, public disclosure, and institutional support." Journal of College Student Development 58.1 (2017): 71-87.

[13] S. Pinder-Amaker. "Identifying the unmet needs of college students on the autism spectrum". Harvard Review of Psychiatry, 22(2), 125-137. 2014.

[14] X. Wei, E.R.A. Christiano, J.W. Wu, J. Blackorby, P. Shattuck, and L.A. Newman. "Postsecondary Pathways and Persistence for STEM Versus Non-STEM Majors: Among College Students with an Autism Spectrum Disorder". Journal of Autism and Developmental Disorders, 44(5):11591167. 2013.

[15] K. Ribu, and T. Patel. "Developing a User-Centered Planning Tool for Young Adults with Development Disorders: A Research Based Teaching Project" In H. Petrie et al (Eds) Universal Design 2016: Learning from the Past, Designing for the Future. IOS press 2016. 